\title{
Development of Entering Order and Work-Volume Assignment Algorithms for the Management of Piping Components in Offshore Structure Construction
}

\author{
Jung Goo Park ${ }^{1} \mathbb{1}$, Ho Jung Kim ${ }^{1}$ and Jong Hun Woo ${ }^{2, *}$ \\ 1 Ship \& Ocean Research Institute, Samsung Heavy Industries, Geoje 53261, Korea; \\ jgbest.park@samsung.com (J.G.P.); hj277.kim@samsung.com (H.J.K.) \\ 2 Naval Architecture and Ocean Engineering, Seoul National University, Seoul 08826, Korea \\ * Correspondence: j.woo@snu.ac.kr
}

Received: 24 October 2020; Accepted: 3 November 2020; Published: 9 November 2020

check for updates

\begin{abstract}
In the early 2010s, with rising oil prices and increasing purchase orders for offshore structures for deep-sea resource development, the shipyards that took these orders suffered unexpected losses. Unlike the construction of commercial carrier vessels, the construction of offshore structures necessary to develop deep-sea resources is difficult to manage due to the complexity of the outfitting process of the topside structure, which is a plant for gas and oil production and treatment. Piping components in particular, which comprise most of the design items, are difficult to manage because they involve 2 to 3 times the man-hours and up to 10 times the quantity of items compared to commercial carrier vessels. Due to not only high man-hours and quantity but also large fluctuations caused by design changes and long procurement lead times, process delays that result in delayed compensation frequently occurred. In response, Samsung Heavy Industries developed an integrated management system for piping components. This study describes the entering order optimization algorithm and work-volume assignment optimization algorithm, which are the core algorithms of this system. The entering order optimization algorithm determines the optimal installation order considering the procurement status of the piping components and the installation readiness status of the installation work site, through which it determines the entering order of the piping components. The algorithm seeks to accelerate the completion rate of installation of the piping components. Next, to minimize delivery delays of sub-contractors to the shipyard, this study developed a work-volume assignment optimization algorithm that can equalize the load on multiple sub-contractors considering the raw material readiness status and the production capacity of the sub-contractors, in terms of materials that must be ordered from external sub-contractors among the piping components whose entering order was determined. Finally, applying the algorithm developed using actual shipyard data resulted in an accelerated completion rate of installation and improved balance of load in terms of volume assigned to the sub-contractors.
\end{abstract}

Keywords: offshore structure; outfitting; piping component; installation readiness status; entering order; work-volume assignment

\section{Introduction}

With the increasing deep-sea development of energy resources for oil and gas, the role of shipyards in charge of drilling vessel and floating platform construction are becoming more 
important ${ }^{1}$. However, compared to previously constructed commercial vessels (oil carrier, container carrier, bulk carrier, etc.), these offshore structures face construction challenges due to the outfitting of the plant (topside structure) that processes gas and oil. According to Back, et al. [1], large shipyards in Korea suffered huge losses due to the offshore structure business. Reports have pointed the complexity of the outfitting process as the key factor affecting these losses [2].

Especially, pipes used to manufacture the plant (topside structure) $)^{2}$ require 2 to 3 times as many man-hours as commercial carrier vessels [1]. For example, compared to the container vessle's outffiting man-hour of about $15 \%$, the FLNG's outffiting man-hour is about $30-40 \%$. Also, with respect to the number of piping components, general transportation vessels require approximately 10,000 pipes, whereas mega liquid gas carriers require 20,000 [3]. However, an offshore structure requires over 100,000 pipes, which is 5 times the amount for mega gas carriers [4]. As a result, offshore structures are difficult to assemble owing to the huge amounts of piping components and their complex connection relationships, which unavoidably raises the complexity of procuring and installing piping components. This problem, which severely threatens the profit structure of large shipbuilders that construct offshore structures, arises from insufficient experience in constructing new types of offshore structures [5]. In particular, inadequate support systems and standardization necessary to manage the process of offshore structure construction leads to this problem [6,7].

Studies on outfitting management including piping components are active within the areas of construction and plant engineering as well. However, if the scope is limited to shipbuilding within the shipbuilding industry, then representative prior research includes the following studies.

First of all, the several studies were conducted regarding the order of installation of outfitting items.

In the research of Lee [8], a five-step technique of focusing improvement included the DBR methodology of the theory of constraint (TOC) and established a solution for delivery delays to prevent delays in the delivery of piping components. This study focused on finding the constraint process and argued that a solution to the pharmaceutical process could mitigate the overall supply chain problems.

Dong, et al. [9] proposed a flexible two-step queuing network model for the planning and accurate execution of the outfitting material installation process. The developed model uses the optimal dynamic control policy and the Markov decision process to obtain the optimal cost. The researchers developed a regression model that calculates the threshold policy empirical approach using data from both dynamic and static models. The results demonstrated that the heuristic model's performance was very close to the optimal value.

Choi and Woo [10] proposed an algorithm that determines the installation order of outfitting materials by considering the process parameters, weights, and installation constraints. They developed an application program for the algorithm and compared it with the outfitting material installation performance in an actual offshore structure, thus verifying the accuracy of the algorithm. Using this study's results to define the installation order of the outfitting materials, the plan's accuracy was improved.

However, these studies are studies that solve the problem of determining the optimal order under the assumption that materials and work conditions are determined, and do not present a plan to cope with the variability of the installation state at the work site.

Next, the following studies were conducted on the procurement between the shipyard and sub-contractor.

1 As of 2020 when this study was written, falling oil prices and decreasing global cargo volume have led to a rapid decline in orders for offshore structures for deep-sea resource development. As the algorithm in this study was developed based on the time when orders for offshore structures peaked in the mid-2010s, there is some difference in the time period regarding the development background.

2 Actual shipyards use the term "spool" rather than "pipe". Strictly classified, a unit module, such as a flange, that is assembled to a pipe and made through a fabrication and bending process is called a spool. This study collectively refers to these as "piping components" to facilitate the understanding of readers in fields other than shipbuilding and plants. 
Wei and Nienhuis [11] proposed an automatic sequence generation method for planning the manufacture of outfitting materials between a shipyard and a manufacturing sub-contractor of the outfitting materials. Based on the results of a field survey, they proposed a mathematical model with parameters of material type, weight, size, installation location, and minimum working distance. The field survey results were analyzed using an analytical hierarchy process (AHP), and the order was determined using a computer-aided design model. They analyzed the work relationship from production to installation and developed a lead time prediction algorithm.

To reduce rework due to scheduling inconsistencies between the installation yard and the manufacturing supplier of the outfitting materials installed on a ship, Rose, et al. [12] proposed a mathematical model to ensure scheduling suitability. They also posed the problem of outfitting material production scheduling using a heuristic algorithm and evaluated the algorithm's suitability. The algorithm enables manufacturing suppliers to determine priorities for production and meet constraints that minimize transportation times for installation.

Chen, et al. [13] applied a routing optimization technique to comply with material supply schedules in shipbuilding. By defining the outfitting material supply problem as a complex vehicle routing problem, they considered the constraints on capacity and various manufacturing sites. They optimized material assignment using a multi-population genetic algorithm (MPGA) and improved delivery compliance by $71 \%$ in comparison to the existing dispatching rules. This is an example of using a genetic algorithm to improve the dispatching rules for delivery in the outfitting material supply problem. However, since only the capacity of the manufacturing site is used as a constraint, this optimization technique has limited applicability.

To supply outfitting material pallets on time, Zhao, et al. [14] developed a mathematical model using a genetic algorithm that can determine the supply order required to optimize the search order for outfitting material pallets. They proposed a mathematical model for picking and batching outfitting material pallets and applied a genetic algorithm that considers the picking characteristics in minimizing delays in the delivery of outfitting materials. In an example application, their model improved compliance with a delivery date by $68 \%$ in comparison to entering the product based on the delivery date.

These studies about procurement between companies can be said to be researches about defining a mathematical model and deriving an optimal solution in consideration of the required quantity and characteristics of the sub-contractor. However, since a more improved method was required in considering the physical properties of materials and urgency rate of the constraints related to the optimization of work-volume assignment in this study, the mathematical model (integer linear program) was selected for the optimization through a review of previous researches.

In terms of the planning and scheduling system, a number of studies can be found outside of the shipbuilding industry. The main trend is the material requirement planning (MRP) methodology developed by Rolls Royce and General Electric in the 1950s, and academically established by Joseph [15]. Since then, it has evolved into MRP II, including master planning, rough-cut capacity planning, and capacity requirement planning [16]. In addition, this planning methodology has been developed into enterprise resource planning (ERP) today and spread to various industries [17]. Moreover, a number of patents related to research using MRP as a core algorithm have also been invented [18-20]. Furthermore, based on these backgrounds, various types of planning systems are commercially used today [21-25]. Most of the planning systems with a MRP algorithm as the core are easy to apply to mass production industries where the product structure is standardized in the bill of material (BOM) and procurement or production lead times for items constituting the BOM are determined.

However, it is impossible to apply these existing planning methodologies in the shipbuilding field of the order-taking industry. In particular, in order to establish a planning system in a shipyard, it is necessary to link with the existing design system and reflect the shipbuilding production planning system [26]. However, the previously MRP-cored planning systems could not reflect the design 
system (e.g., Tribon or Aveva marine) and BOM structure of the shipbuilding sector, and also failed to customize into the shipbuilding production planning system. Therefore, it is very common for the shipbuilding industry of a certain size or larger, where the information system investment is possible, to use their own self-developed planning system.

\section{Objective}

The target shipyard has been developing an integrated management system for the piping components management system ${ }^{3}$ as a part of the target shipyard's planning and scheduling system. The integrated management system for piping components seeks to optimize the installation order and work-volume assignment to sub-contractors considering the material readiness status, installation readiness status, and work-load estimation of sub-contractors. Figure 1 shows a configuration of the target management system.

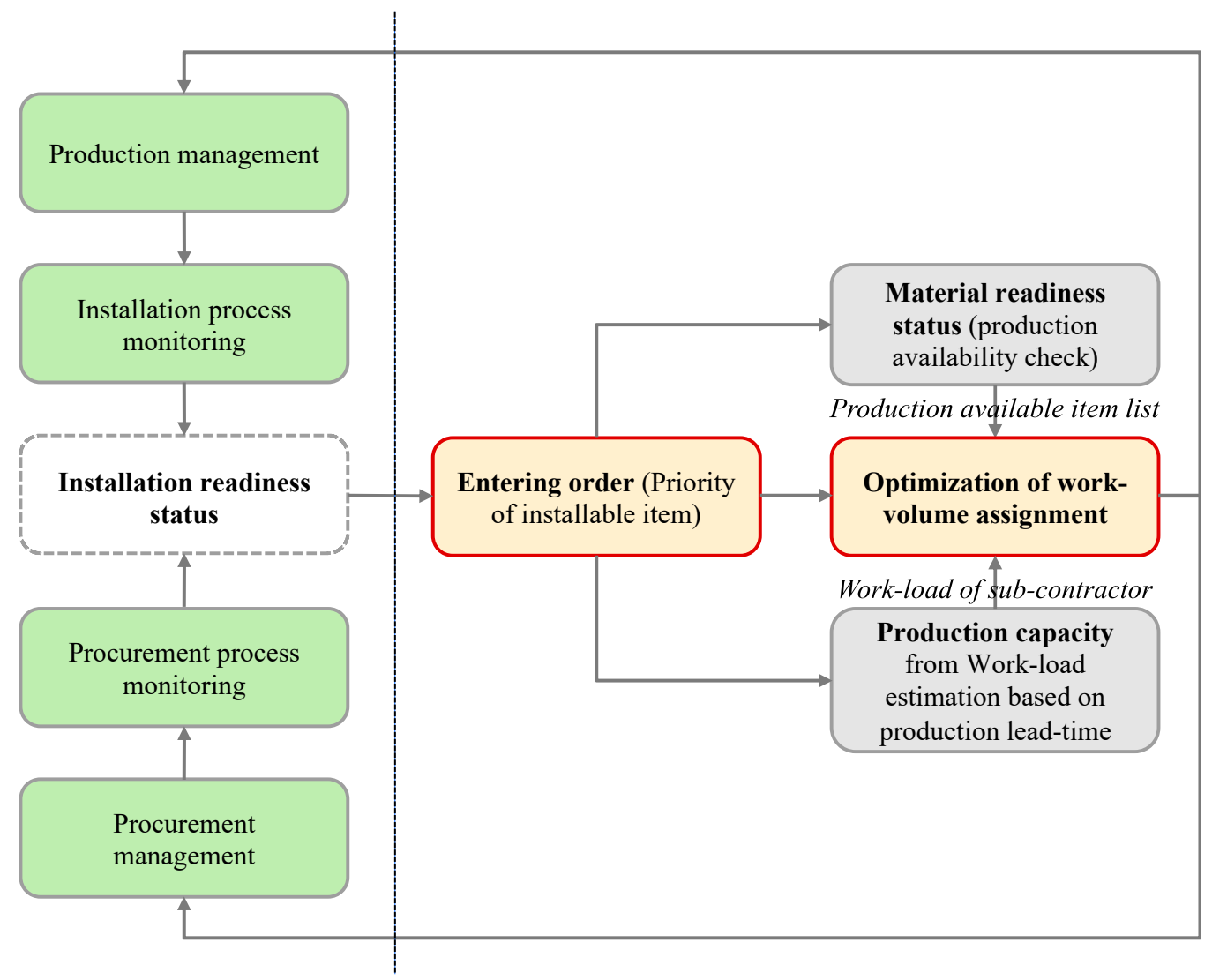

Figure 1. Integrated management system for piping components and research target of this paper (box with red boundary).

This study aims to develop an entering order ${ }^{4}$ optimization and work-volume assignment optimization algorithms for the integrated management system for piping components. The scope of this paper is limited to pipes, which have the greatest impact on process delays among the various types of piping components (pipes, supports, flanges, valves, etc.).

3 The SHI integrated management system for piping components was developed on the operating system Windows Server 2016 (version 1803) using the language C\#, the development tool MS Visual Studio, and the database system Oracle DB.

4 Entering order: In this study, "entering" means either procurement from a sub-contractor manufacturer who manufactures the pipe or movement of an already-manufactured pipe from the warehouse to the site to await installation. 
For the first algorithm, the entering order optimization, an entering order optimization method is needed that considers the installation readiness status. Since the test process (the last process in the piping component installation) takes the longest amount of time, the higher the installation rate of the continuously connected piping components is, the earlier the testing process can be completed, thereby minimizing process delays. If the entering order is determined without considering the installation readiness status, then piping components that cannot be installed are entered, thus increasing the congestion of the installation site or preventing piping components that can be installed from being entered and delaying the installation of other piping components that have a connection relationship with that item. To accelerate the completion rate of piping components, an entering order optimization algorithm must be developed that considers the installation readiness status.

Next, the work-volume assignment optimization algorithm is required for a balanced procurement between shipyards and sub-contractor manufacturers where piping components are installed. Even though the shipyard determines the optimal entering order, process delays are unavoidable if the sub-contractors cannot meet the delivery time of each piping component [27]. The most important part of the decision process for the timely procurement of piping components is the assignment of work-volumes among the sub-contractors. Due to the inefficiency of the existing assignment methods, which are performed manually, firms require a method for systematically assigning production work-volumes based on actual process data. To optimize the assignment of work-volumes for piping components to sub-contractors, an algorithm must be developed that assigns the work-volumes according to the capacity and work-load constraints of each sub-contractor.

The configuration of this paper is as follows. Section 3 describes the developed algorithm. In detail, Section 3.1 describes the installation readiness status and entering of the order optimization algorithm for optimizing the entering order, and Section 3.2 describes the work-volume assignment and work-volume assignment optimization algorithm. Section 4 describes the results of applying the developed algorithms. In detail, Section 4.1 describes the application results of the entering order optimization algorithm and Section 4.2 describes the application results of the work-volume assignment optimization algorithm.

\section{Algorithm Development}

\subsection{Entering Order Optimization Algorithm}

In the shipyard, the installation readiness status of piping components is referred to as the piping installation status. When installing piping components, installation work can be started when at least three consecutive pipes are ready. An algorithm that determines the entering order is required to maximize the number of pipe materials that can be completely installed in order to minimize the waiting materials.

As illustrated by the example in Figure 2, the number of pipes that can be completely installed varies depending on which pipes are selected to be entered among the unentered piping components. Therefore, the number of pipes that can be installed depends on the completion rate of installation, which varies with each pipe's entering order and can be quantified based on the connection relationships. Suppose, for example, that for the status represented on the top of Figure 2, two pipes remain to be installed as indicated by the empty gray boxes. To increase the installation completion rate, it is necessary to determine which of these two piping components should be installed first and to determine the entering order based on this. In Case 1, the number of piping components that can be completely installed increases to four as the No.1 material is entered, whereas in Case 2, the number of piping components that can be completely installed is three (not considering the end pipe). The number of piping components that can be completely installed is influenced by the number of piping components already installed. Therefore, if the entering order changes, depending on the status of the pipes already installed, the number of piping components to be completely installed will be different. This impacts the planning of the following test process. The test process is a major process that takes a long time; therefore, the higher the initial completion rate is secured, the lower the probability of the process delay is. 


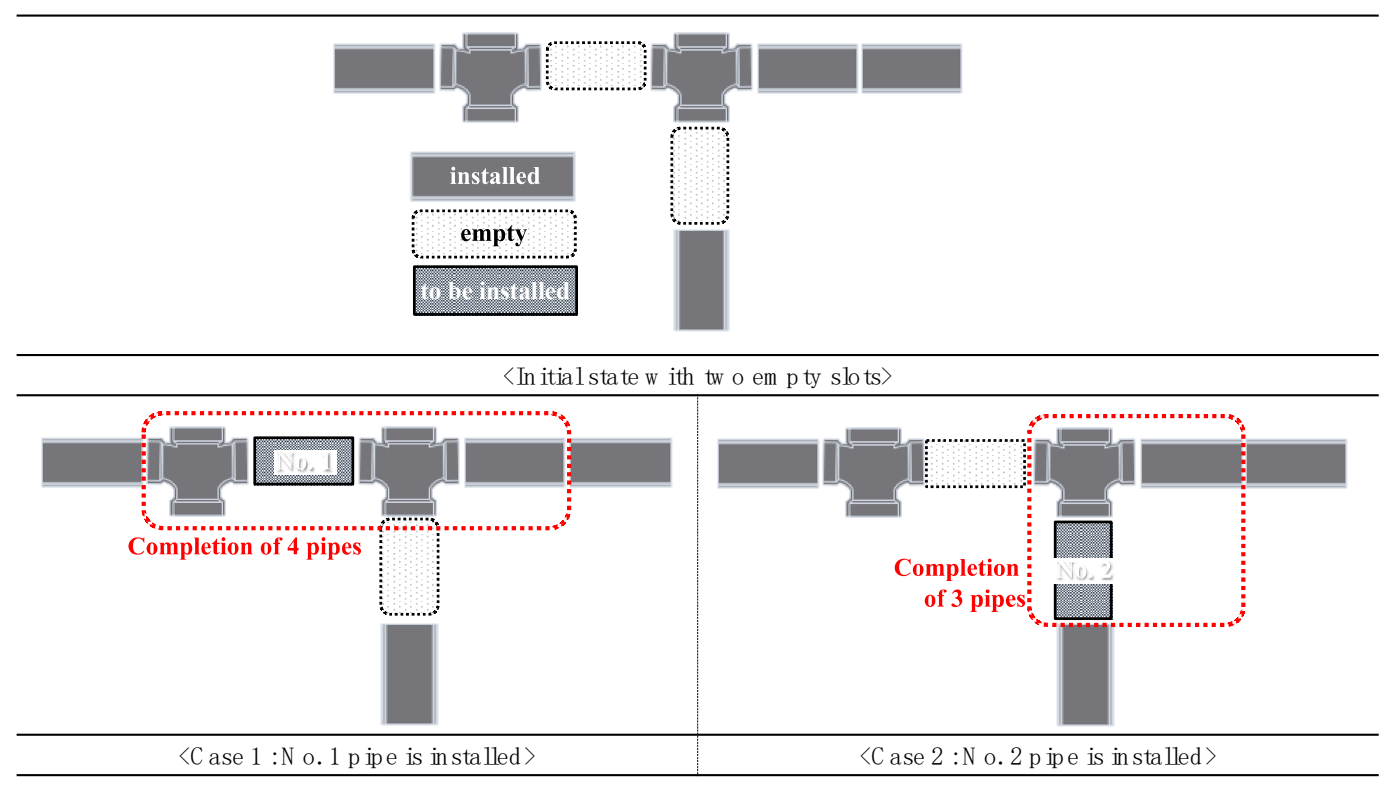

Figure 2. Difference in the number of pipes installed.

Based on this, the algorithm for the entering order can be set up as shown in Figure 3. The installation status of each pipe is checked, and the number of pipes that can be completely installed is calculated, taking into consideration the connection relations among pipes. The number of pipes that can be installed is calculated, and the entering order corresponding to the highest number of pipes that can be installed is determined. The detail algorithm of connection relation identification from CAD is added in Appendix A.

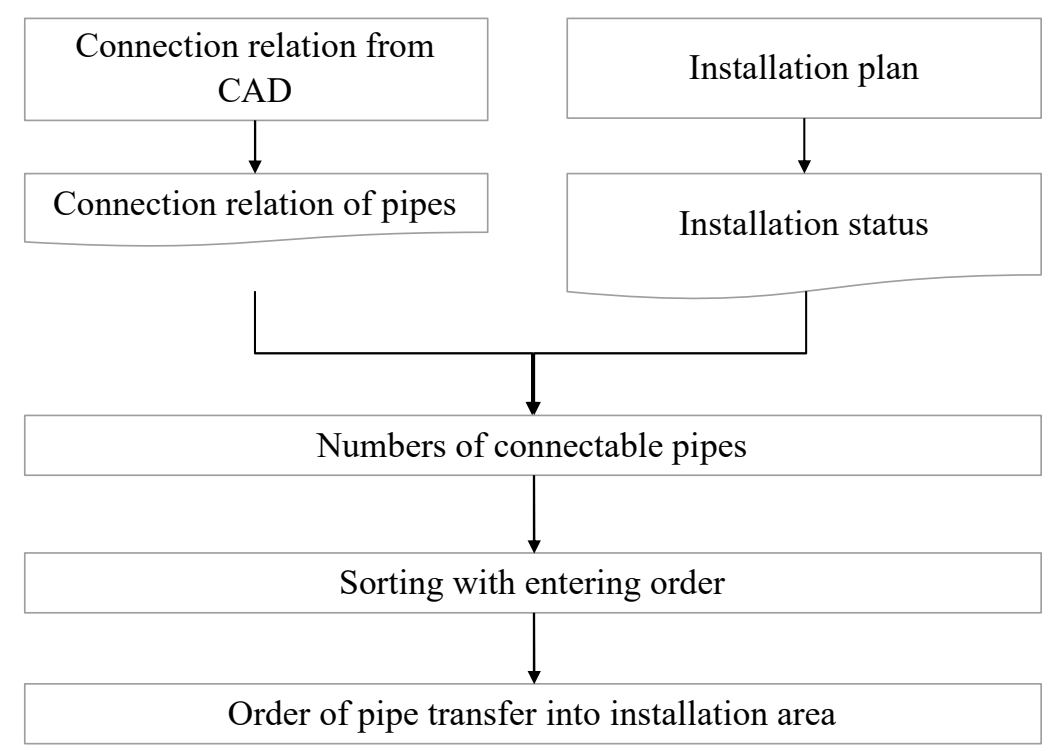

Figure 3. The algorithm that determines the order of transfer into the installation area.

This sorting algorithm can be set up as shown in Figure 4, where $P$ indicates the connection relationships among pipes as a matrix that can reflect the connection relation information from the CAD program. $S$ represents the current installation status as a matrix. $X$ represents the matrix that assumes the receipt of each installation pipe. The number of items that can be completely installed is found by changing the values in the $X$ matrix. $L$ indicates the final calculated value of the number of pipes that can be completely installed for each pipe type. A pipe is considered to be completely installable if 
the value of $L$ is 2 or more. For the $L$ matrix to have a value of 2 or more, it must also be possible to install the surrounding connected pipes. The total number of pipes that can be installed when the $j^{\text {th }}$ item is received is calculated, and the receipt order is determined by ranking the calculated values in descending order.

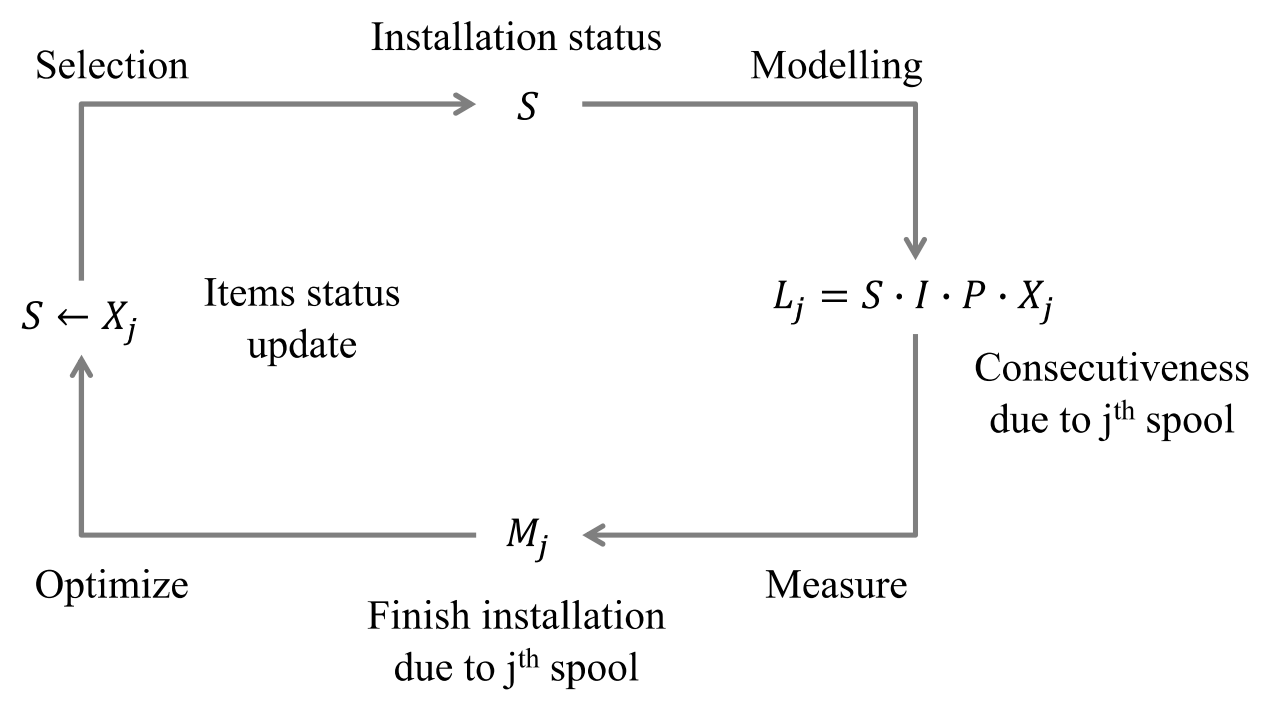

Figure 4. The algorithm of the entering order for piping components.

The proposed algorithm can be expressed by (1)-(3). The matrix that represents the possibility of connection, depending on the receipt of a pipe, was defined as $P^{*}$. To calculate the $P^{*}$ matrix, $S$, which was defined as a vector, was redefined as an $\mathrm{N} \times \mathrm{N}$ square matrix. Thus, the $P^{*}$ matrix can be calculated as follows:

$$
\begin{gathered}
P^{*}=\left[\begin{array}{c}
P_{1}^{*} \\
P_{2}^{*} \\
\vdots \\
P_{N}^{*}
\end{array}\right]=\left[\begin{array}{c}
s_{1} \cdot P_{1} \\
s_{2} \cdot P_{2} \\
\vdots \\
s_{N} \cdot P_{N}
\end{array}\right]=\left[\begin{array}{ccccc}
s_{1} & 0 & 0 & \ldots & 0 \\
0 & s_{2} & 0 & \ldots & 0 \\
0 & 0 & s_{3} & \ldots & 0 \\
\vdots & \vdots & \vdots & \ddots & \vdots \\
0 & 0 & 0 & \ldots & s_{N}
\end{array}\right]\left[\begin{array}{ccccc}
p_{11} & p_{12} & p_{13} & \ldots & p_{1 N} \\
p_{21} & p_{22} & p_{23} & \ldots & p_{2 N} \\
p_{31} & p_{32} & p_{33} & \ldots & p_{3 N} \\
\vdots & \vdots & \vdots & \ddots & \vdots \\
p_{N 1} & p_{N 2} & p_{N 3} & \ldots & p_{N N}
\end{array}\right] \\
=\left[\begin{array}{cccc}
s_{1} p_{11} & \ldots & s_{1} p_{1 N} \\
\vdots & \ddots & \vdots \\
s_{N} p_{N 1} & \ldots & s_{N} p_{N N}
\end{array}\right]
\end{gathered}
$$

Matrix P represents the connection among pipes, which is extracted from the CAD model, and matrix $P^{*}$ is the connection among pipes that are installable, determined by considering the incoming status of each pipe. If the value of the $S$ matrix is 0 , the corresponding row of the $P^{*}$ matrix has a value of 0 . When the current state of the installed pipes is confirmed (represented by $S$ ), the number of installable pipes can be represented by vector $L$, as shown in (2). Each element of vector $L$ represents the number of items that are installable.

$$
L=\left[\begin{array}{c}
l_{1} \\
l_{2} \\
\vdots \\
l_{N}
\end{array}\right]=P^{*} \cdot S=\left[\begin{array}{ccc}
s_{1} p_{11} & \ldots & s_{1} p_{1 N} \\
\vdots & \ddots & \vdots \\
s_{N} p_{N 1} & \ldots & s_{N} p_{N N}
\end{array}\right]\left[\begin{array}{c}
s_{1} \\
s_{2} \\
\vdots \\
s_{N}
\end{array}\right]
$$


Vector $S$ is updated as $S_{j}^{\prime}$ when the $j^{\text {th }}$ pipe is received. The number of additional connected pipes $\left(L_{j}\right)$ can be expressed as shown in (3) when pipe $j$ is added:

$$
L_{j}=\left[\begin{array}{c}
l_{1} \\
l_{2} \\
\vdots \\
l_{j} \\
\vdots \\
l_{N}
\end{array}\right]=P^{*} \cdot S_{j}^{\prime}
$$

$L_{j}$ is the number of pipes that can be connected to the already installed pipes when the $j^{\text {th }}$ pipe is installed. Among the elements of this calculated vector $L_{j}$, the largest value is defined as $M_{j}$. Accordingly, as $M_{j}$ increases, more pipes are connected, thereby raising the entering priority. A simple example is described in Appendix B.

\subsection{Work-Volume Assignment Optimization Algorithm}

After the entering order is determined, the work-volume must be assigned to the sub-contractors (sub-contractors) who manufacture the piping components. Conventionally, work-volumes of piping components are mostly assigned manually or depend on the experience of the operator. However, with consistent delivery delays, it was determined that each sub-contractor's unbalanced workload had the greatest impact. This highlights the necessity of rationally assigning work-volume.

To assign work-volumes, the production capacity of each sub-contractor should be evaluated first. Production capacity was defined as the number of units that can be processed per day. To assign the work-volume that can be processed by each sub-contractor, the slot concept, as shown in Figure 5, was introduced. Each slot represents the production capacity of a sub-contractor and is filled with the work-volume. The daily work status can be monitored based on the status of each slot. The work-volume remaining in the current slot was calculated as the total work-volume of materials, depending on the production site, from the start of production to the final production stage. The work-volume assignment is performed daily with newly created work-volumes from the design stage.

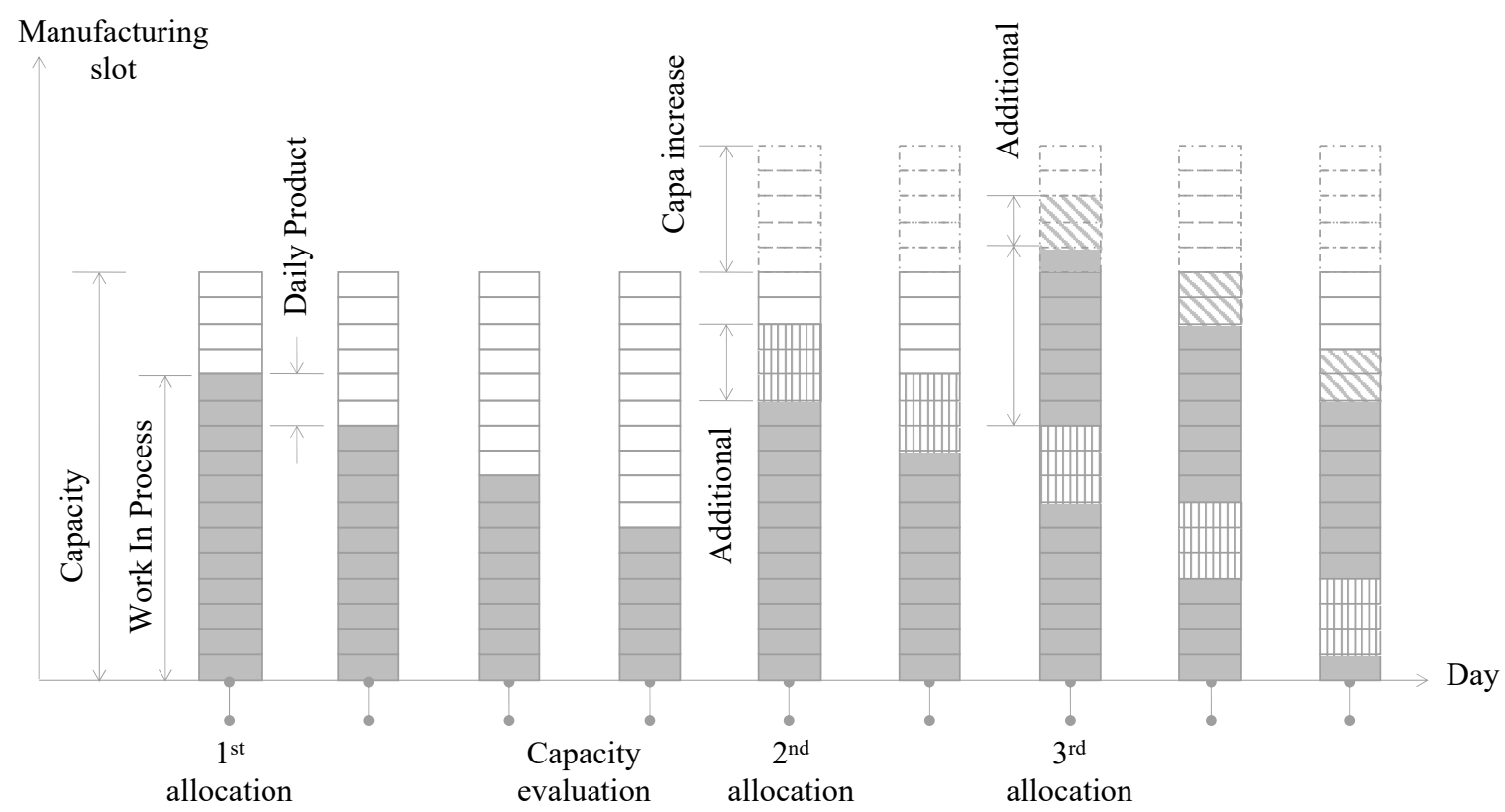

Figure 5. Conceptual diagram for consideration of production capacity of the pipe manufacturer. 
The entire process of work-volume assignment can be explained as follows. First, the system evaluates the production capacities of each sub-contractor. It then calculates the assignable workvolume by subtracting work-in-process (WIP) from the previously calculated production capacity. Then, the assignment of the 1st phase is conducted so that the workload is evenly distributed among the sub-contractors with respect to the assignable work-volume. The additional work-volume is assigned by considering the production capacity of each sub-contractor from the 2nd phase sequentially until the completion of work-volume assignment.

The linear optimization problem was defined to assign the work-volume (the volume unit is defined as the welding length in this study) to the slots of each sub-contractor. Linear programming involves the optimization of linear objective functions while satisfying the given linear constraints. A linear program consists of decision variables, an objective function, and constraints. In an optimization problem, the decision variables represent the quantities to be determined; they should minimize or maximize the objective function, which comprises the linear function of the decision variables. The decision variables must satisfy the constraints, i.e., the constraints or requirements of the system. The constraints must comprise the linear function of the decision variables and be expressed as an equality or inequality [28]. In general, in linear programming, integer linear programming is applied when all of the decision variables are integers, and mixed-integer linear programming when only some of the decision variables are integers. This study applied mixed-integer linear programming because the decision variable is mixed with integer and non-integer value.

The goal of the optimization was to balance the work-volume assigned to each sub-contractor based on their production capacity. To this purpose, a unit workload was defined to determine whether the work-volume assigned to a manufacturing sub-contractor was appropriate. Here, the unit workload ${ }^{5}$ of a certain pipe is defined as the work-volume per day (m/day). Moreover, the condition whether the given pipe order could be manufactured by the sub-contractor, based on the product material and the detailed process required for the production is considered. Then, the production capacity $^{6}$ was defined as the same unit with a unit workload. The unit workload defined in this way is reflected in $\operatorname{cum}_{i, t}$, which is the sum of workloads allocated to sub-contractor $i$ at time $t$. In addition, the production capacity is allocated as the value of the sub-contractor's production capacity defined as $O D C_{i}$.

The optimization model was developed as follows with the dicision variables and model parameters those are shown in Box 1:

(1) Difference in the ratio of work-volume assigned to the production capacity among the subcontractors was minimized.

(2) Difference in the ratio of work-volume assigned to the work-volume by urgency level among the sub-contractors was minimized.

(3) Constraints are applied requiring that any piping component be assigned to only one subcontractor and that all piping components should be assigned.

Using the decision variables and parameters defined above, the objective function was expressed as shown in (4). The objective function minimizes the difference in the workload between each sub-contractor, as well as the difference in work-volume for each urgency level.

$$
\begin{aligned}
& \min \left\{w_{1} \sum_{i} \sum_{t} I D_{i, t}+w_{2} \sum_{i} \frac{E O A_{i}-E U A_{i}}{r_{a} \sum_{p} w_{p}}\right. \\
& \left.\quad+w_{3} \sum_{i} \frac{E O B_{i}-E U B_{i}}{r_{b} \sum_{p} w_{p}}+w_{4} \sum_{i} \frac{E O C_{i}-E U C_{i}}{r_{c} \sum_{p} w_{p}}\right\}
\end{aligned}
$$

5 For example, if the production time of a certain pipe is 10 days, the unit workload was defined as $0.1 \mathrm{~m} /$ day.

6 For example, if any sub-contractor can manufacture 300 pipes, and the unit workload of each of pipe is $0.1 \mathrm{~m} / \mathrm{day}$, then the production capacity of the sub-contractor is going to be $30 \mathrm{~m} /$ day. 
Box 1. Decision variables and model parameters.

Decision variables

- $x_{p, i} \in\{0,1\}:$ Indicates whether a product has been assigned to a manufacturing sub-contractor. One pipe must be assigned to one manufacturing sub-contractor. $P$ refers to the product, and $i$ refers to the manufacturing sub-contractor.

- $L O D_{i, j, t}$ : Positive difference in the assigned workload required at time $t$ for manufacturing sub-contractors $i$ and $j$.

- $\quad L U D_{i, j, t}$ : Negative difference in the assigned workload required at time $t$ for manufacturing sub-contractors $i$ and $j$.

- $\quad I D_{i, t}=L U D_{i, j, t}-L O D_{i, j, t}$ : Maximum difference in the ratio of the assigned workload required at time $t$ for manufacturing sub-contractors $i$ and $j$.

- $E O A_{i}, E O B_{i}, E O C_{i}$ : Positive difference in the ratio of normal, quasi-urgent, and urgent materials to the total assigned process requirements of the assigned materials for manufacturing sub-contractor $i$.

- $E U A_{i}, E U B_{i}, E U C_{i}$ : Negative difference in the ratio of normal, quasi-urgent, and urgent materials to the total assigned process requirements of the assigned materials for manufacturing sub-contractor $i$.

Model parameters

- $\quad \operatorname{poss}_{p, i}$ : Whether manufacturing sub-contractor $i$ can produce material $p$; set to 0 or 1 , depending on the material type.

- $a_{p}, b_{p}, c_{p}$ : Whether the urgency of the delivery request for material $p$ is normal, quasi-urgent, or urgent, expressed as $a$ normal, $b$ quasi-urgent, or $c$ urgent.

- $r_{a}, r_{b}, r_{c}$ : Ratio of normal, quasi-urgent, and urgent workloads among the workloads required for the entire assigned process.

- $s d_{p}, e d_{p}$ : Start and end dates of the manufacturing process of material $p$.

- $w_{p}$ : Required process workload of material $p$.

- $\quad \operatorname{cum} W_{i, t}$ : Total workload already assigned due to the previous assignment result on date $t$ for manufacturing sub-contractor $i$.

- $w_{1}, w_{2}, w_{3}, w_{4}$ : Weights expressing the importance of each term in the objective function.

- $O D C_{i}$ : Production capacity of manufacturing sub-contractor $i$.

The following conditional functions were developed to express the constraints on the objective function defined above. First, there must be at least one sub-contractor who can produce each pipe; this constraint is expressed by (5). Next, one pipe must be assigned to only one sub-contractor; this constraint is expressed by (6). (7) expresses the difference in the workload assigned to the sub-contractors, which must be a positive value. (8) expresses the difference in the ratio assigned for each production urgency level, which must also be a positive value.

$$
\begin{gathered}
x_{p, i} \leq \operatorname{poss}_{p, i} \\
\sum_{i} x_{p, i}=1 \\
\frac{\left(O D C_{i}-c u m W_{i, t}-\sum_{p} \frac{1}{e d_{p}-s d_{p}} \times w_{p} \times x_{p, i}\right)}{O D C_{i}} \\
-\frac{\left(O D C_{j}-c u m W_{j, t}-\sum_{p} \frac{1}{e d_{p}-s d_{p}} \times w_{p} \times x_{p, j}\right)}{O D D C_{j}} \\
=L U D_{i, j, t}-L O D_{i, j, t} \leq I D_{k, t} \\
r_{a} \sum_{p}\left(w_{p} \times x_{p, i}\right)-\sum_{p}\left(a_{p} \times w_{p} \times x_{p, i}\right)=E O A_{i}-E U A_{i} \\
r_{b} \sum_{p}\left(w_{p} \times x_{p, i}\right)-\sum_{p}\left(b_{p} \times w_{p} \times x_{p, i}\right)=E O B_{i}-E U B_{i} \\
r_{c} \sum_{p}\left(w_{p} \times x_{p, i}\right)-\sum_{p}\left(c_{p} \times w_{p} \times x_{p, i}\right)=E O C_{i}-E U C_{i}
\end{gathered}
$$




\section{Results}

To verify the effectiveness of the entering order optimization algorithm and work-volume assignment optimization algorithm presented above, the algorithms were applied to a case study using actual shipyard data.

\subsection{Result of the Entering Order Optimization Algorithm}

To verify the entering order optimization algorithm, this study analyzed a zone containing about 400 pipes. Table 1 shows the number of installation-completed pipes when applying the existing manual method and the proposed entering order optimization algorithm to a problem of determining the entering order for 400 pipes (there are 528 pipes in total, and 400 pipes to be installed). Expressed as a graph in Figure 6, the number of installation-completed pipes increases as the pipe installation proceeds. Compared to the existing method, the increase rate of installation-completed pipes sharply rises when applying the proposed entering order algorithm. This signifies that even if the installation of all pipes is completed at the same time, the more pipes that complete the installation early, the earlier the test process can be conducted, thus minimizing process delays. Hence, the test process, a major bottleneck process in offshore plant construction, can be started earlier and proceed more smoothly by securing more connection relationships early.

Table 1. Comparison of the rate of installation-completed pipes.

\begin{tabular}{ccccccc}
\hline Installation No. & $\mathbf{0}$ & $\mathbf{5 0}$ & $\mathbf{1 0 0}$ & $\mathbf{2 0 0}$ & $\mathbf{3 0 0}$ & $\mathbf{4 0 0}$ \\
\hline Existing Method & $0.0 \%$ & $10.8 \%$ & $15.5 \%$ & $33.3 \%$ & $62.9 \%$ & $100 \%$ \\
\hline Proposed Algorithm & $0.0 \%$ & $28.2 \%$ & $49.3 \%$ & $70.5 \%$ & $93.5 \%$ & $100 \%$ \\
\hline Difference & $0.0 \%$ & $17.4 \%$ & $33.8 \%$ & $37.2 \%$ & $30.6 \%$ & $0.0 \%$ \\
\hline
\end{tabular}

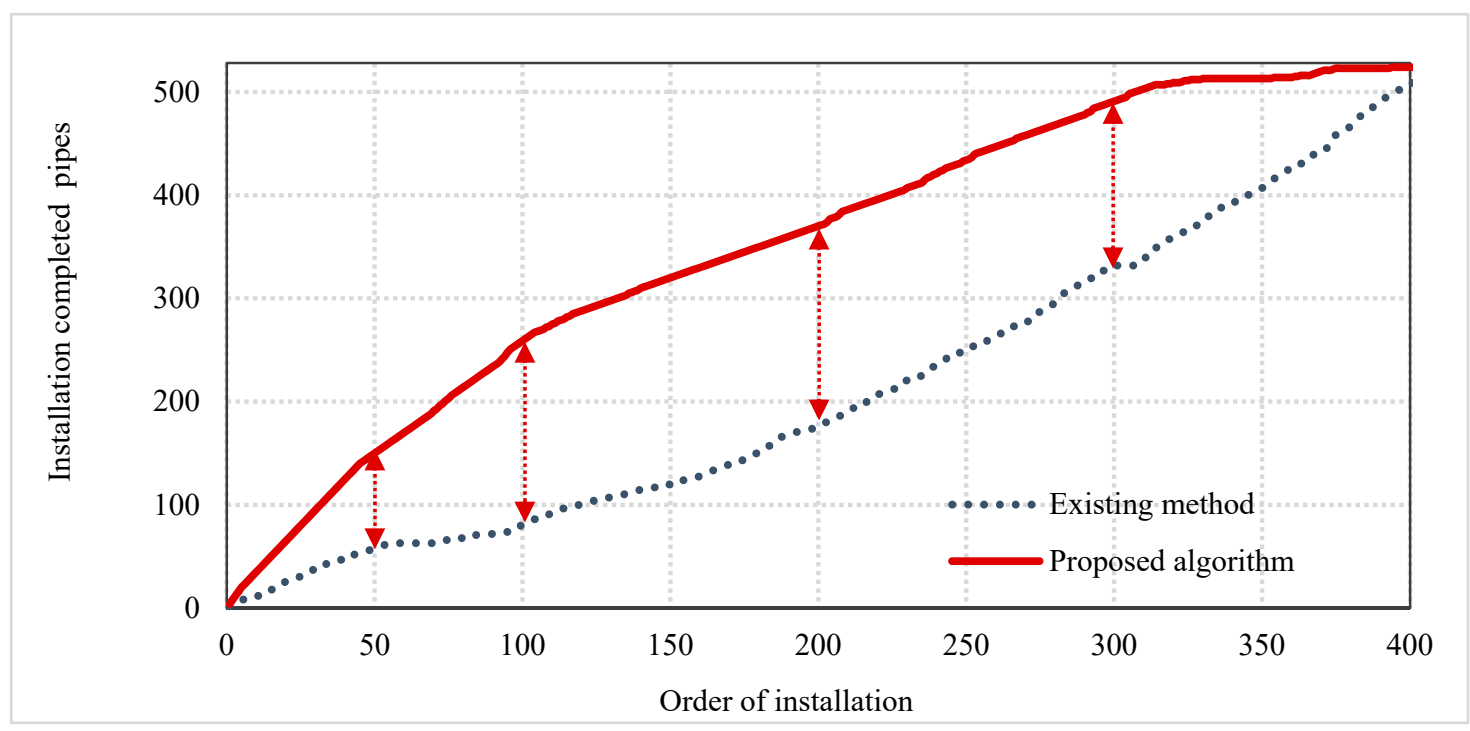

Figure 6. Comparison of the progress rate of installation-completed pipes before and after applying the entering order algorithm (target block 101).

Figures 7-9 show the results of the entering order algorithm for additional blocks. Figure 7 shows determining the entering order for 310 pipes (there are 482 pipes in total, and 172 pipes already installed), Figure 8 shows determining the entering order for 506 pipes (there are 761 pipes in total, and 255 pipes already installed), and Figure 9 shows determining the entering order for 620 pipes (there are 818 pipes in total, and 198 pipes already installed). As can be seen from each graph, it can be concluded that the outfitting delay of the corresponding block can be prevented by providing 
a sufficient time buffer for the late installation process such as a test by showing a high completion rate in all cases.

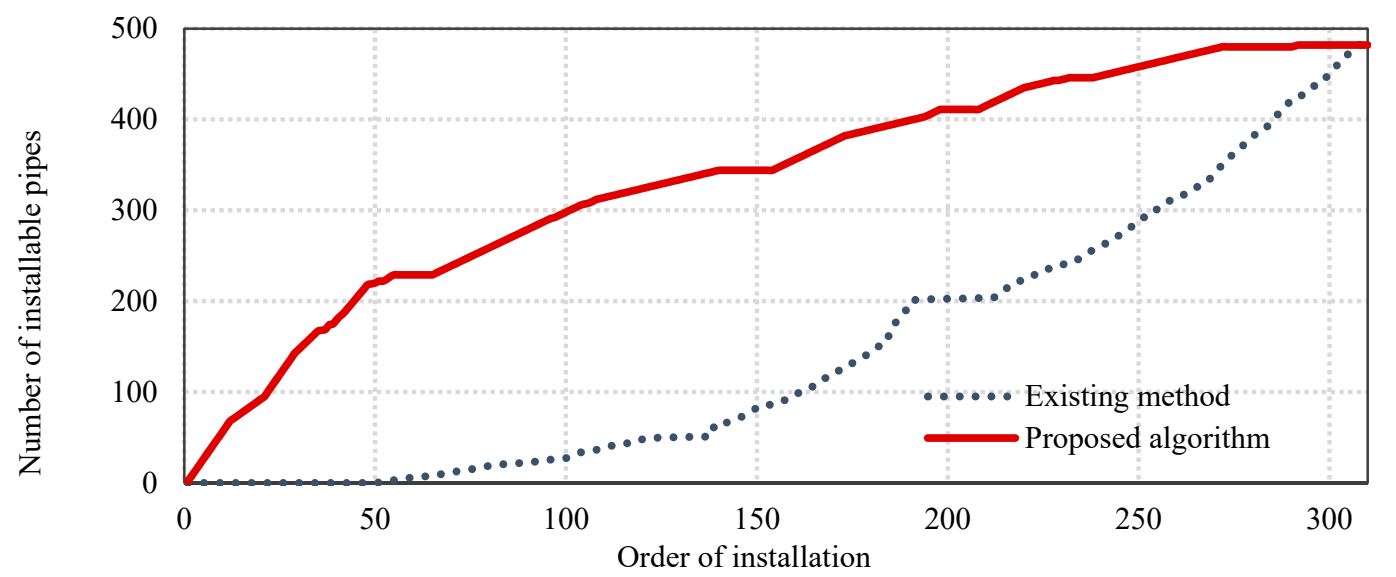

Figure 7. Comparison of the progress rate of installation-completed pipes before and after applying the entering order algorithm (target block 102).

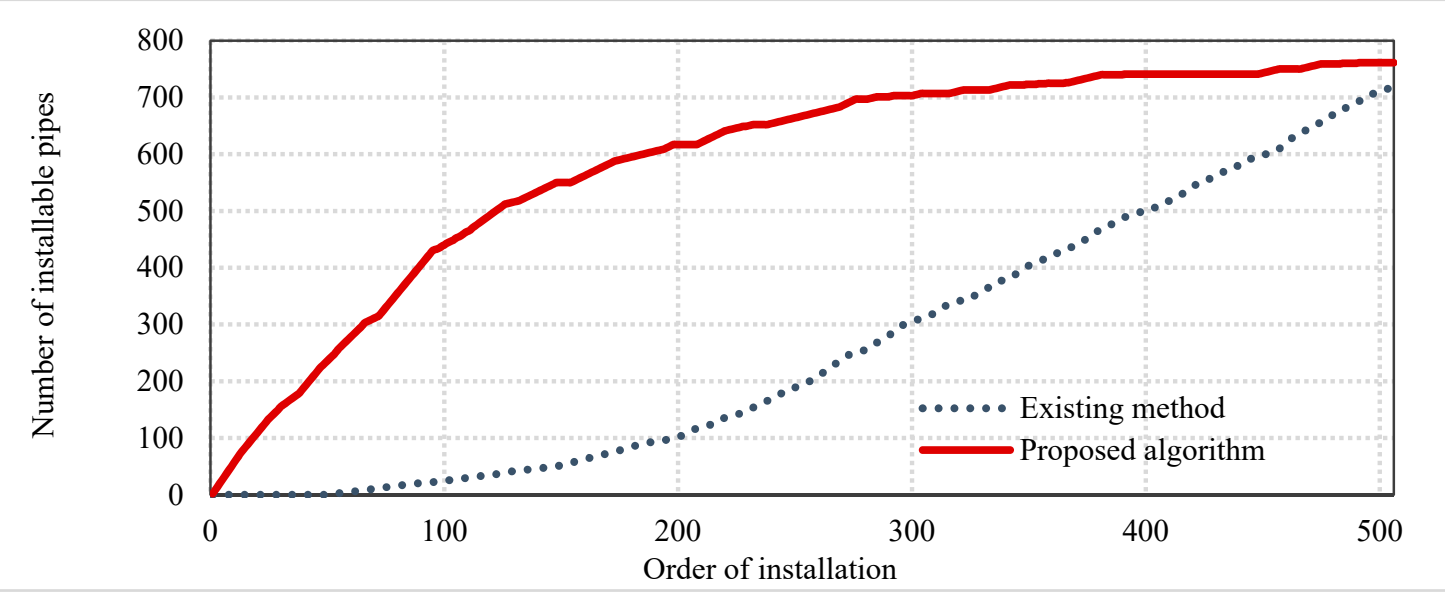

Figure 8. Comparison of the progress rate of installation-completed pipes before and after applying the entering order algorithm (target block 103).

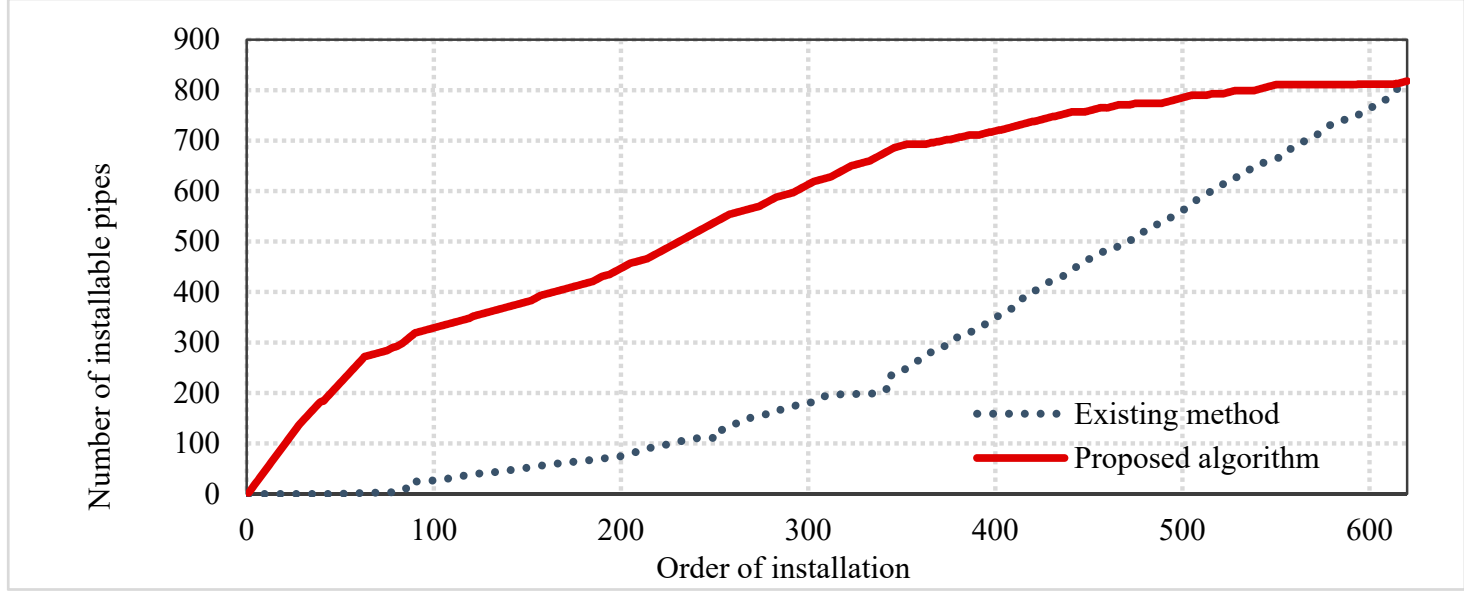

Figure 9. Comparison of the progress rate of installation-completed pipes before and after applying the entering order algorithm (target block 104). 


\subsection{Result of the Work-Volume Assignment Optimization Algorithm}

Next, to verify the effectiveness of the optimization algorithm of assigning work-volumes for which the entering order was determined, the algorithm was applied to an actual offshore structure. For the work-volumes of 11 sub-contractors, the work-volume instructions issued during a specific period were assigned and compared. The number of target pipes is 3254 and the total workload is $350,782 \mathrm{~m}$. In addition, the urgent ratios are $0.7,0.2$, and 0.1 as normal, quasi-urgent, and urgent, respectively. The initial workload of each sub-contractor is assumed as 0 . Moreover, the planned start and finish date of each pipe are also considered.

To compare the process loads of the sub-contractors after assigning work-volumes, the production capacity of each sub-contractor and the process state at the start of the comparison were set to the same value. If the work-volume assignment target was a special material type that could be allocated only to a specific sub-contractor, then no difference between the assignment methods could be identified. Therefore, only products with material types capable of production by at least two sub-contractors were considered in the comparison of assignment methods.

Table 2 compares the results of the operator's assignment and that of the assignment algorithm. The 11 sub-contractors were classified from A to K, and the production capacity of each sub-contractor was evaluated in the same unit. As the difficulty of applying subjective judgment may increase with the increasing problem complexity for the manual assignment method, it was assumed that there were no WIP or inventory. Based on the production capacity of the sub-contractors, the algorithm was tested with the goal of equalizing the process load with respect to the production capacity.

Table 2. Comparison of manual and optimization work-volume assignment results.

\begin{tabular}{cccccc}
\hline \multirow{2}{*}{ Sub-Contractor } & Capacity $(\mathbf{m})$ & \multicolumn{2}{c}{ Manual Assignment } & \multicolumn{2}{c}{ Optimization Assignment } \\
\cline { 3 - 6 } & & Allocation & Workload & Allocation & Workload \\
\hline A & 53,000 & 39,270 & $74 \%$ & 38,176 & $72 \%$ \\
B & 25,000 & 22,950 & $92 \%$ & 20,643 & $83 \%$ \\
C & 105,000 & 89,474 & $85 \%$ & 79,569 & $76 \%$ \\
D & 10,500 & 1599 & $15 \%$ & 7131 & $68 \%$ \\
E & 33,200 & 23,201 & $70 \%$ & 21,325 & $64 \%$ \\
F & 45,000 & 18,886 & $42 \%$ & 31,921 & $71 \%$ \\
G & 22,500 & 15,950 & $71 \%$ & 12,755 & $57 \%$ \\
H & 63,500 & 24,773 & $39 \%$ & 48,317 & $76 \%$ \\
I & 18,500 & 10,586 & $57 \%$ & 16,312 & $88 \%$ \\
J & 78,000 & 73,562 & $94 \%$ & 49,484 & $63 \%$ \\
K & 35,000 & 30,531 & $87 \%$ & 25,149 & $72 \%$ \\
AVG & - & - & $66 \%$ & - & $72 \%$ \\
STDV & - & - & 0.25 & - & 0.089 \\
\hline
\end{tabular}

For sub-contractors A, B, C, and E, the manual and algorithm work-volume assignment results were very similar. This was attributed to the fact that only two sub-contractors can manufacture most of the material types to be produced; therefore, there can be no large differences between the automatic and manual assignments. Overall, the average load factor of the sub-contractor companies increased by approximately $6 \%$ from 0.66 for the manual assignment to 0.72 for the algorithm assignment. The standard deviation of the process load factor decreased from 0.25 for the manual assignment to 0.089 for the algorithm assignment, indicating an increase in load leveling.

Since only sub-contractor A, C, E, and F can produce urgent orders, an additional analysis with urgency consideration is conducted with cases of A, C, E, and F. Table 3 compares the work-volume assignment results with the urgency level for the four sub-contractors with urgent and quasi-urgent assignments. As the objective was to achieve a workload evening for each sub-contractor according to the urgency level, the standard deviations for each urgency level were compared. As shown in Table 3, 
the standard deviations were significantly reduced by assignment with optimization in comparison to the manual assignment.

Table 3. Comparison of manual allocation and automatic allocation results with respect to the urgency rate.

\begin{tabular}{ccccccc}
\hline \multirow{2}{*}{ Sub-Contractor } & \multicolumn{3}{c}{ Manual Allocation } & \multicolumn{3}{c}{ Automatic Allocation } \\
\cline { 2 - 7 } & U & Q & N & U & Q & N \\
\hline A & $41 \%$ & $12 \%$ & $47 \%$ & $10 \%$ & $20 \%$ & $70 \%$ \\
C & $4 \%$ & $13 \%$ & $82 \%$ & $4 \%$ & $14 \%$ & $82 \%$ \\
E & $50 \%$ & - & $50 \%$ & $5 \%$ & $13 \%$ & $82 \%$ \\
F & - & - & $100 \%$ & $7 \%$ & $8 \%$ & $85 \%$ \\
STDV & 0.25 & 0.07 & 0.26 & 0.03 & 0.05 & 0.07 \\
\hline
\end{tabular}

U: Urgent; Q: Quasi-urgent; N: Normal.

Figure 10 compares the daily workload of manual and optimization algorithm application for emergency volume distribution during 10 days, that is the emergency planning period. In addition, Figure 11 shows the standard deviation of daily workloads among sub-contractors. On the first day of work, for example, the standard deviation of workload of each sub-contractor was 0.16 in the manual plan, but when the optimization algorithm was applied, the workload evening level was reduced to 0.05 , increasing the level of load leveling. It can be seen that the overall workload deviation is improved even in the 2-10 day interval. This means that the work-volume has been assigned in a reasonable manner, and this means that the process at each sub-contractor is stabilized and the probability of supplying the product to the yard in a timely manner increases.
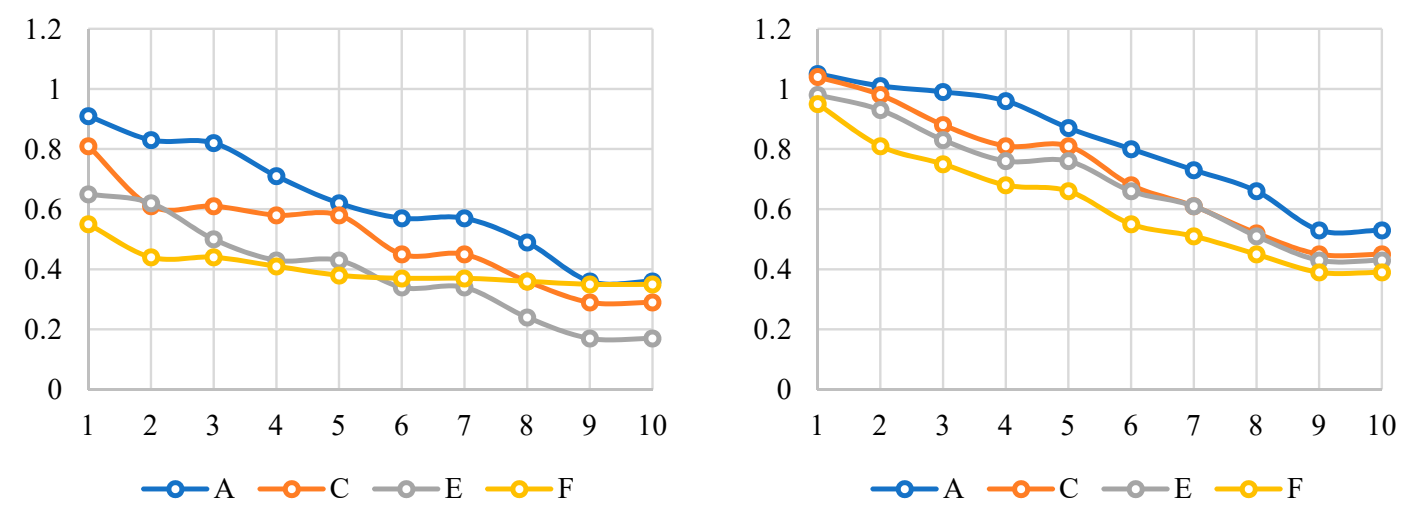

Figure 10. Comparison of daily workload of A, C, E, and F (Left graph: daily workload distribution when manually planned; Right graph: daily workload distribution when planned with optimization algorithm).

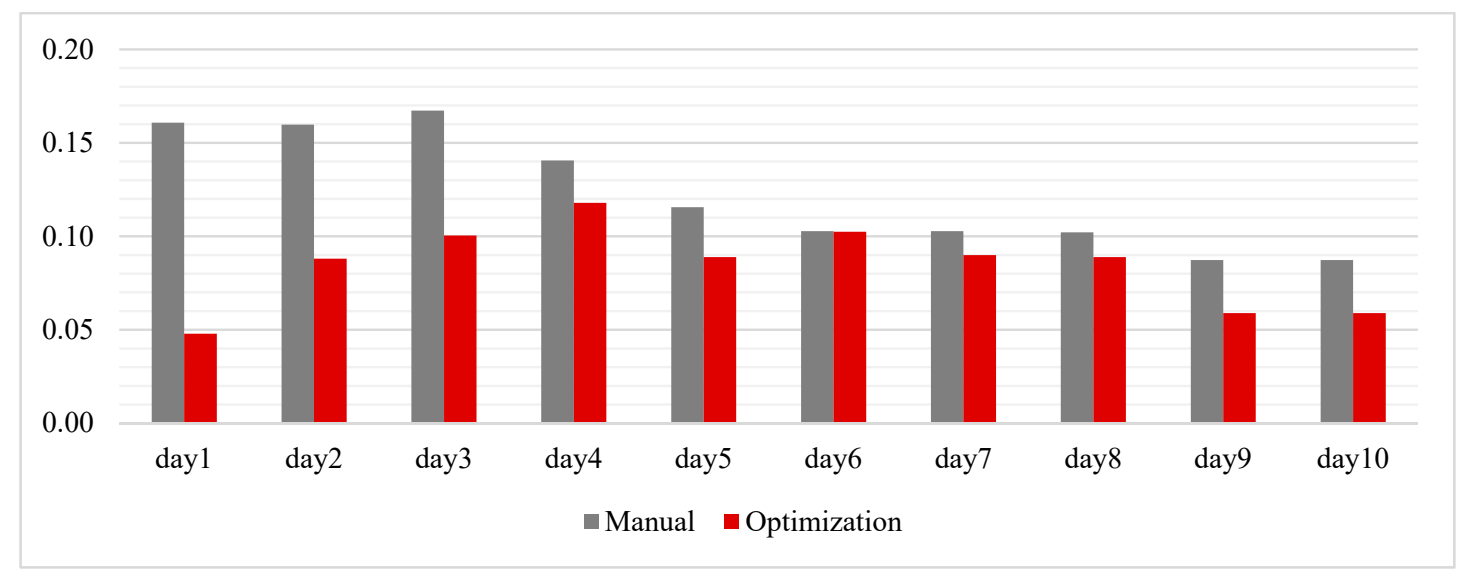

Figure 11. Standard deviation of workload deviation. 
Using the entering order algorithm developed through this study, the order of pipe installation was determined according to the priority of installation. In addition, the order to be supplied by the sub-contractors was decided according to the order of installation determined in this way. While optimally assigning the work-volume to be produced through assignment optimization, the actual sub-contractors can maintain a uniform workload.

As a result, the integrated management system for piping components (Figure 1) was developed and it was possible to stably supply pipes without delaying the production period. By applying the developed system to the actual offshore structure construction, it was possible to obtain a result that the timely procurement rate, that was less than $50 \%$ before the system development, was improved to more than $90 \%$ after the system is developed.

\section{Conclusions}

Compared to commercial carrier vessels, offshore structures are more likely to suffer losses from process delays due to the complexity of the outfitting process in terms of construction. The piping components needed to manufacture the topside structure of offshore structures require 2 to 3 times the man-hours and 5 to 10 times the quantity of items compared to commercial carrier vessels, thus creating limitations in existing management methods.

To solve this problem, Samsung Heavy Industries developed an integrated management system for the procurement and installation of piping components. The integrated management system for piping components was developed to minimize process delays by monitoring the status of shipyards and sub-contractors and linking the design and management systems.

This study described the development of two key algorithms among the modules that constitute the integrated management system for piping components, that is, an algorithm that optimizes the entering order considering the installation readiness status, and an algorithm that optimizes the sub-contractors' work-volume assignment of sub-contractors considering the workload estimation of the sub-contractors.

Furthermore, this study confirmed that applying the entering order optimization algorithm to actual piping components increased the completion rate of installation more than the existing manual method (the section with the largest difference showed a 30\% completion rate). This accelerated installation completion rate increases the rate at which the test process (the greatest factor in process delays) can be started early, thereby helping minimize process delays.

Next, applying the work-volume assignment optimization algorithm to the work-volume assignment of sub-contractors improved the workload between sub-contractors by approximately $6 \%$ compared to the existing method (Table 2). In addition, it was confirmed that the workload balancing level was improved even for frequently occurring emergency orders. As a result, through the development of an integrated management system for piping components with optimization algorithms, the timely procurement rate could be achieved from less than $50 \%$ to more than $90 \%$.

Future research will enhance the performance of the integrated management system for piping components by improving the accuracy of the procurement lead time prediction module to over $90 \%$ based on machine learning, which is in the testing stage, and applying it to the current fixed lead time-based systems.

Author Contributions: Conceptualization, J.G.P.; methodology, J.G.P.; software, H.J.K.; validation, J.G.P. and Woo, J.H.W.; formal analysis, J.G.P.; investigation, J.H.W.; data curation, H.J.K.; writing_original draft preparation, J.H.W.; writing-review and editing, J.H.W.; visualization, J.G.P.; supervision, J.H.W.; project administration, J.G.P.; funding acquisition, J.H.W. All authors have read and agreed to the published version of the manuscript.

Funding: This research was supported by the following research projects: 1 . The new faculty startup fund from Seoul National University; 2. IoT- and AI-based Development of the Digital Twin for Block Assembly Process (20006978) of the Korean Ministry of Trade, Industry, and Energy; 3. Mid-Sized Shipyard Dock and Quay Planning Integrated Management System (20007834) of the Korean Ministry of Trade, Industry, and Energy.

Conflicts of Interest: The authors declare no conflict of interest. 


\section{Appendix A. Connection Relation of Pipes from CAD}

The installation relationships refer to information on connections between installation materials, in particular, to check which material is connected based on what sequence. To obtain the connection relationship information, this study developed an algorithm for recognizing and automatically extracting items required to check a piping component supply rate from the plant design management system (PDMS), which is a computer aided design (CAD) system used by most shipbuilding companies. The connections between items are basic information for managing a piping component supply rate. It is necessary to configure leading and following connection relationships between various sensor items for collecting data generated from pipes comprising pipe line, pipe supports, various valves, and various sensors for collecting data from fluid flow.

To extract the connection relationships between outfittings, in-line items were identified from the PDMS information as shown in Figure A1. The in-line items refer to spools, supports, valves, and instruments, which are main items that are important for the pipeline setup. As for pipes, which are the core of the pipeline, the information of spools can be identified through the pipe name registered in a design process. Pipe names can identify unique members because its duplication is not allowed. The coordinate of the center of the pipe and the connected drawings can be extracted, which is required by the piping components supply rate inspection system, from the information of the corresponding pipe. Furthermore, the information of pipe support can be also identified as a unique item through a pipe support name. A pipe support does not have a serial connection relationship with the spool, valve, and instrument, but is a dependent item of the pipe or valve. The pipe support information is mapped to the pipe information and output together. However, the relationship of pipes and supports is N:N mapping because one support can support multiple pipes. In addition, the valve and instrument information can be obtained from the PDMS information, and this can be identified as a unique item as well. The valve and instrument information can be divided into a case where it has a serial connection relationship with the pipe or a dependent relationship with the pipe. If it is not a serial connection relationship, the branch information was output additionally.
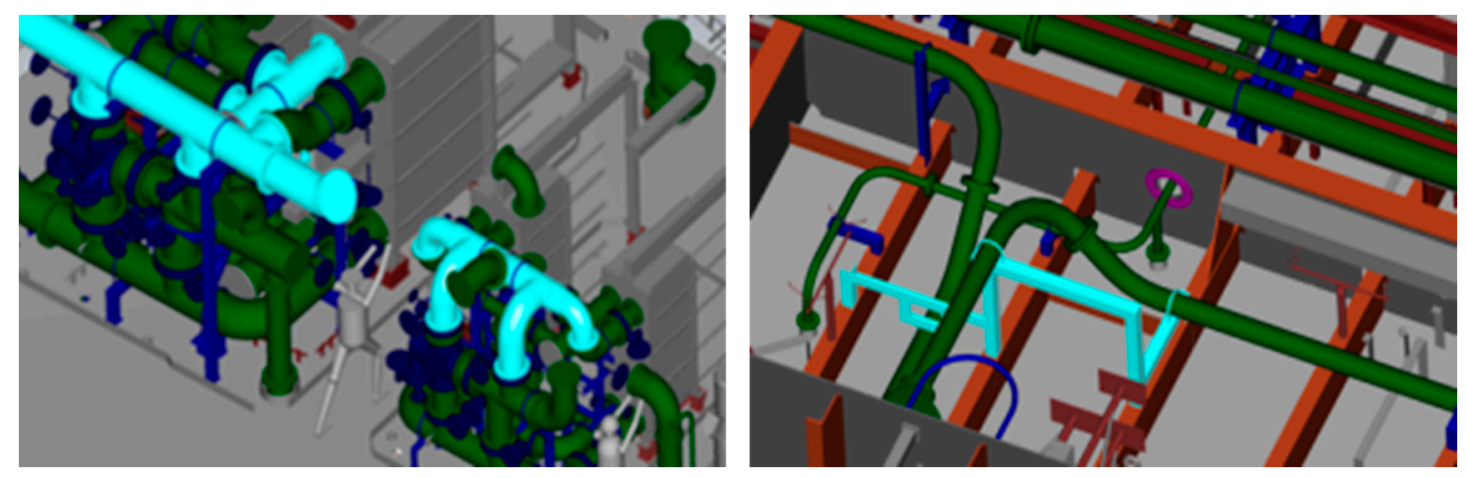

Figure A1. Recognition of in-line items in the plant design management system (PDMS) (spool, support, valve, instrument).

The list of each item was defined in installation units for CAD information definition of each item comprising a piping component supply rate in the PDMS system, and the items included in the installation unit were pipes, support, valve, and instrument. For each item list, items located at the start and end connections were defined. The start item was defined as an item on the leading side on the flow of the fluid while the end item as an item on the following side so that the connection sequence can be defined in line with the flow direction of the fluid. Welding information, as an information separator that is in charge of the connection between pipes, was also an output if welding between pipes exists in addition to the valve and instrument. The connected information was identified by defining the item that is connected again after this information that is in charge of connection. This information was defined as a property of the installation unit item, and the valve and instrument were distinguished 
by defining a detailed type in the property information. If there is no detailed type in the property information, it was defined by the weld line information, which can be used as information that defines the connection method between pipes.

The PDMS is largely divided into the PDMS spooler and PDMS design as shown in Figure A2. The algorithm was set up to analyze the connection sequence data by combining the data extracted from each subsystem. The PDMS spooler contains major in-line items required for installation, and the PDMS design contains the support information and the structure of the installed location. Figure A3 shows structures and layers of data included in the PDMS module. Each data consists of spool information, field information, and attachment information that belongs to each item. The spool and field information contain information about the start and end of each item, and the attachment information contains the information of materials for connecting each item. Through the information of these materials, the connection method between materials and the list of materials required for connection can be checked. The information of support and instrument also has a structure similar to the PDMS design. Support does not have attachment information because it has no separate installation material. The instrument has the information of gasket or flange for middle connection as attachment information. Figure A4 indicates the logic in finding the connection relationship from the items defined above. Each connection relationship separates the pipe and property information from each block installation item as well as finds and maps each attachment information. The system was implemented to collect data from the PDMS through the logic described above and perform pretreatment.

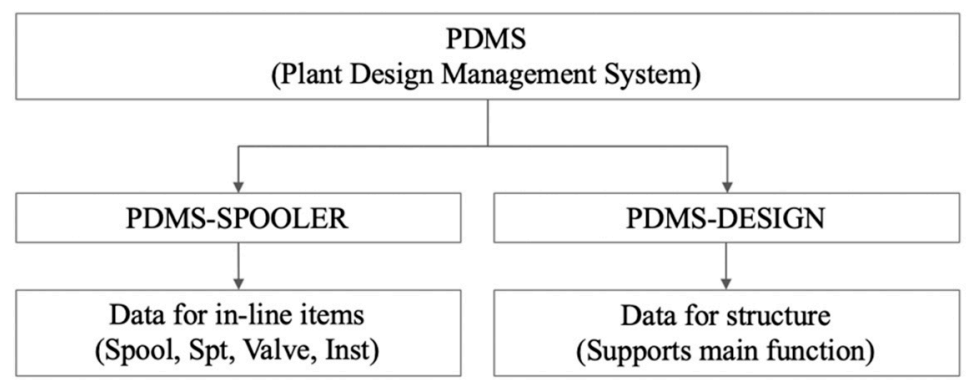

Figure A2. System structure by installation item of PDMS.

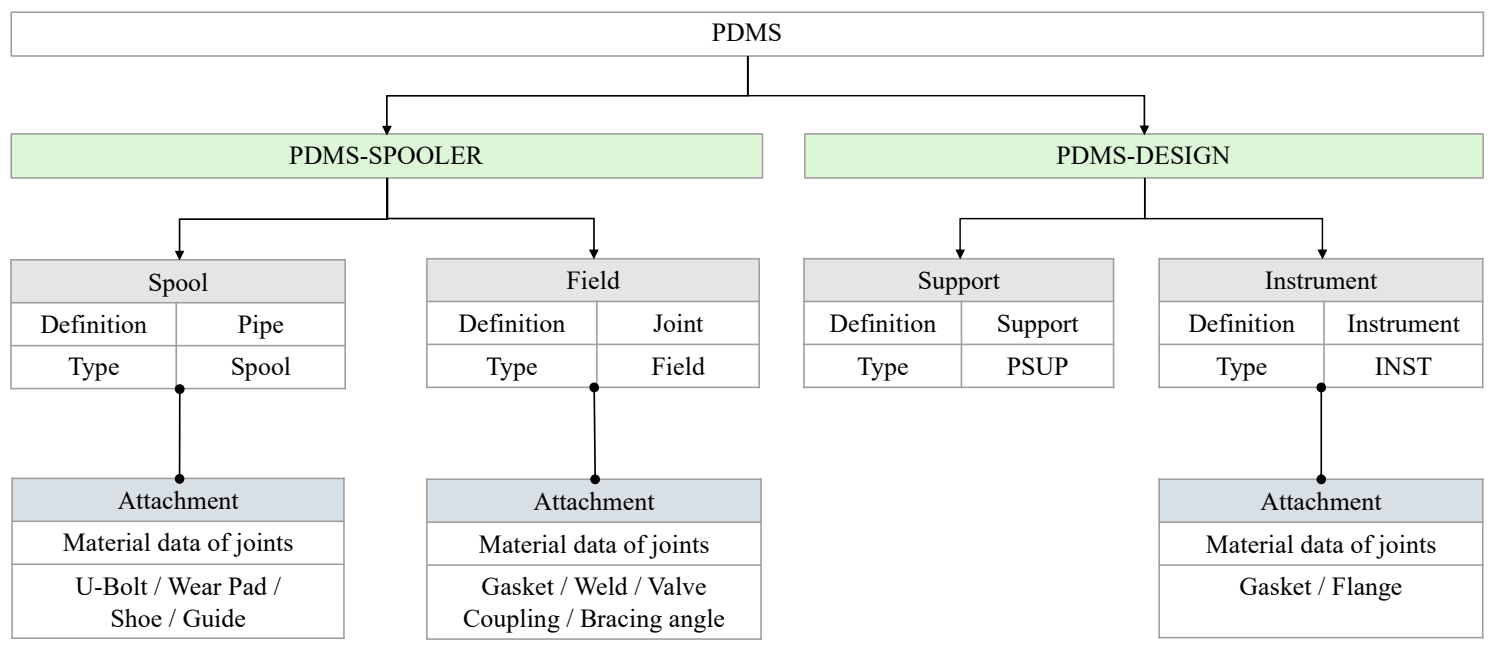

Figure A3. CAD system data structure for connection relationship information extraction. 


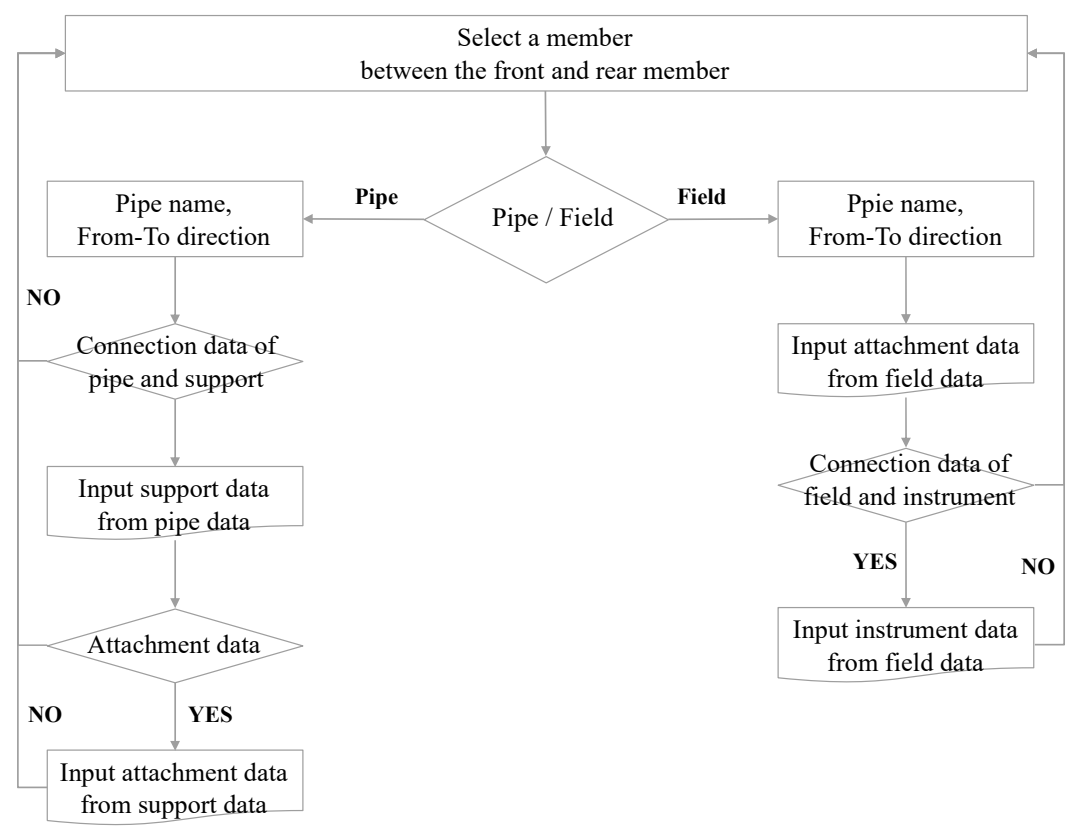

Figure A4. Data analysis algorithm for extracting connection relationships between installation items.

The preprocessed data are saved in a database to set the connection relationships. Even a simplelooking pipeline has several hundreds of installation items. The connection relationships between installation items extracted in each pipeline unit are aligned and stored in the database. A macro-program for automatic extraction was developed to acquire information periodically from the PDMS, and the connection relationship data that are updated in specific cycles were acquired automatically using the program.

The extracted data are aligned and processed in line with the connection sequence in accordance with the data processing logic described above. The PDMS data extraction and data processing were set as batch tasks so that they can be updated with new information in the middle of a design process. Furthermore, in order for designers to distinguish temporarily stored information and the information used for actual production, the consistency between a bill of material (BOM) with a completed drawing output and a BOM extracted from CAD information was checked before they are stored in the database. Thus, the items in the connection information extracted first were compared with the BOM details in the ERP system. The items that do not match with the BOM were found and classified as items that are in the process of the drawing output and excluded from the connection relationship information. The connection sequences were rearranged through this second data processing, and the final connection sequence data were confirmed. The data were made to be usable in actual production through the first and second data refining and processing steps.

\section{Appendix B. Simple Problem of Entering Order Decision}

A practical case can be defined, as shown in Figure A5, to set up a model and explain the proposed algorithm. Installation pipes from 1 to 11 are connected as shown in Figure A5, and the installed pipes are expressed by the $S$ matrix. The slot of Pipe 2 in the $S$ matrix is represented by a value of 0 because it has not been installed yet, and items that have been installed are represented by a value of 1 . In the case of the $P$ matrix, which represents the connection relationships among pipes, a value of 1 indicates that a connection between pipes is ensured. The $X$ matrix assumes receipt of the relevant pipe. If pipe 2 is received, the second value in the $X$ matrix changes from 0 to 1 , and the $L$ matrix, which represents the number of connectible pipes, is calculated. The value of $M$ represents the number of installable pipes when pipe 2 is installed. The connections of pipes 1,2 , and 3 are completed, and a value of 1 is 
obtained by excluding the existing pipes 1 and 3. Finally, an algorithm that increases the receipt order of a pipe with the largest number of connected pipes is obtained.

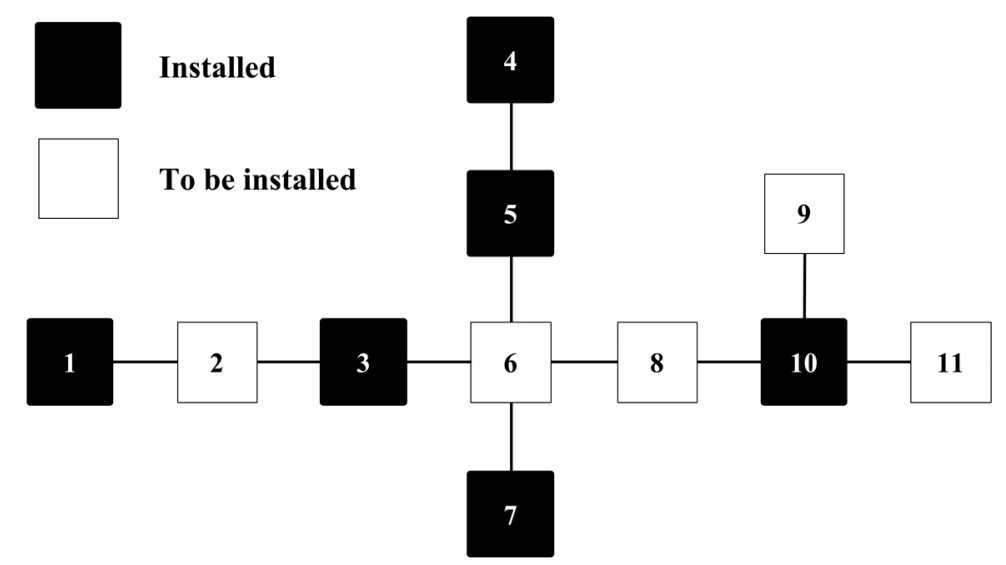

Figure A5. Test model for verifying the entering order algorithm.

In the case of the above example, the $P^{*}$ matrix, $\mathrm{S}$ matrix, and $\mathrm{L}$ matrix can be expressed as shown in Equations (A1)-(A3). As shown in Equation (A3), after $L_{j}$ is calculated for pipes 2, 6, 8, 9, and 11 in the empty state in Figure 4, since the largest value of $M_{6}$ corresponding to $L_{6}$ is 3, pipe 6 is confirmed to have the highest entering priority. Therefore, in the example illustrated in Figure A5, the most advantageous plan, with respect to the pipe installation completion rate, is to enter pipe 6 first.

$$
\begin{aligned}
& \begin{aligned}
P^{*} & =\left[\begin{array}{lllllllllll}
0 & 1 & 0 & 0 & 0 & 0 & 0 & 0 & 0 & 0 & 0 \\
1 & 0 & 1 & 0 & 0 & 0 & 0 & 0 & 0 & 0 & 0 \\
0 & 1 & 0 & 0 & 0 & 1 & 0 & 0 & 0 & 0 & 0 \\
0 & 0 & 0 & 0 & 1 & 0 & 0 & 0 & 0 & 0 & 0 \\
0 & 0 & 0 & 1 & 0 & 1 & 0 & 0 & 0 & 0 & 0 \\
0 & 0 & 1 & 0 & 1 & 0 & 1 & 1 & 0 & 0 & 0 \\
0 & 0 & 0 & 0 & 0 & 1 & 0 & 0 & 0 & 0 & 0 \\
0 & 0 & 0 & 0 & 0 & 1 & 0 & 0 & 0 & 1 & 0 \\
0 & 0 & 0 & 0 & 0 & 0 & 0 & 0 & 0 & 1 & 0 \\
0 & 0 & 0 & 0 & 0 & 0 & 0 & 1 & 1 & 0 & 1 \\
0 & 0 & 0 & 0 & 0 & 0 & 0 & 0 & 0 & 1 & 0
\end{array}\right] \\
S & =\left[\begin{array}{lllllllllll}
1 & 0 & 0 & 1 & 1 & 0 & 1 & 0 & 0 & 1 & 0
\end{array}\right]^{T}
\end{aligned} \\
& S_{2}^{\prime}=\left[\begin{array}{lllllllllll}
1 & 1 & 0 & 1 & 1 & 0 & 1 & 0 & 0 & 1 & 0
\end{array}\right]^{T} \\
& S_{6}^{\prime}=\left[\begin{array}{lllllllllll}
1 & 0 & 0 & 1 & 1 & 1 & 1 & 0 & 0 & 1 & 0
\end{array}\right]_{T}^{T} \\
& S_{8}^{\prime}=\left[\begin{array}{lllllllllll}
1 & 0 & 0 & 1 & 1 & 0 & 1 & 1 & 0 & 1 & 0
\end{array}\right]_{T}^{T} \\
& S_{9}^{\prime}=\left[\begin{array}{lllllllllll}
1 & 0 & 0 & 1 & 1 & 0 & 1 & 0 & 1 & 1 & 0
\end{array}\right]^{T} \\
& S_{11}^{\prime}=\left[\begin{array}{lllllllllll}
1 & 0 & 0 & 1 & 1 & 0 & 1 & 0 & 0 & 1 & 11
\end{array}\right]^{T}
\end{aligned}
$$

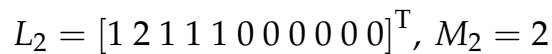

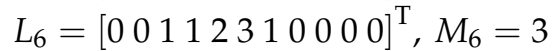

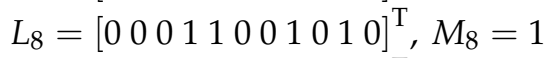

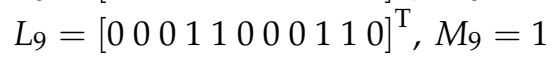

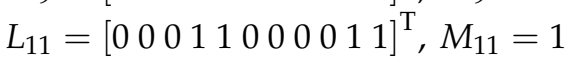




\section{References}

1. Back, M.G.; Woo, J.H.; Lee, P.; Shin, J.G. Productivity improvement strategies using simulation in offshore plant construction. J. Ship Prod. Des. 2017, 33, 144-155. [CrossRef]

2. Speight, J.G. Offshore platforms. In Handbook of Offshore Oil and Gas Operations, 1st ed.; Elsevier: Waltham, MA, USA, 2014.

3. Lee, J.H.; Kim, S.H.; Lee, K. Integration of evolutional BOMs for design of ship outfitting equipment. Comput. Aided Des. 2012, 44, 253-273. [CrossRef]

4. Park, M.G.; HAN, M.; Kim, W.K. A study on the engineering support system for offshore outfitting design. Adv. Sci. Technol. Lett. 2013, 42, 125-128.

5. Westby, O. Estimation of man-hours for fabrication of ships and offshore platforms. J. Ship Prod. 2009, 25, 78-87.

6. Wang, P.; Mohamed, Y.; Abourizk, S.M.; Rawa, A.T. Flow production of pipe spool fabrication: Simulation to support implementation of lean technique. J. Constr. Eng. Manag. 2009, 135, 1027-1038. [CrossRef]

7. Han, M.K.; Kim, W.K.; Park, M.G. Development of a collaboration system based on mobile framework in the field of ships and marine industry. Int. J. Multimed. Ubiquitous Eng. 2014, 9, 121-126. [CrossRef]

8. Lee, H.S. A Case Study on Improvement of Pipe Outfitting Production Process Using TOC; University of Ulsan: Ulsan, Korea, 2013.

9. Dong, F.; Deglise-Hawkinson, J.; Van Oyen, M.P.; Singer, D. Dynamic control of a closed two-stage queueing network for outfitting process in shipbuilding. Comput. Oper. Res. 2016, 72, 1-11. [CrossRef]

10. Choi, J.H.; Woo, J.H. Algorithm development for the spool installation sequence of outfitting works in offshore structure. J. Mar. Sci. Technol. 2020, 1-16. [CrossRef]

11. Wei, Y.; Nienhuis, U. Automatic generation of assembly sequence for the planning of outfitting processes in shipbuilding. J. Ship Prod. Des. 2012, 28, 49-59. [CrossRef]

12. Rose, C.; Coenen, J.; Hopman, H. Definition of ship outfitting scheduling as a resource availability cost problem and development of a heuristic solution technique. J. Ship Prod. Des. 2016, 32, 154-165. [CrossRef]

13. Chen, G.; Jiang, Y.; Sheng, X.; Wang, J.; Jia, H. Workstation-oriented distribution optimization of shipbuilding materials. In Proceedings of the MATEC Web of Conferences, Abu Dhabi, UAE, 20-22 November 2018.

14. Zhao, D.; Jiang, Y.; Bao, J.; Wang, J.; Jia, H. Study on batching and picking optimization of marine outfitting pallets. In Proceedings of the MATEC Web of Conferences, Abu Dhabi, UAE, 20-22 November 2018.

15. Joseph, O. Material Requirements Planning; McGraw-Hill: New York, NY, USA, 1975.

16. Hopp, W.J.; Spearman, M.L. To pull or not to pull: What is the question? Manuf. Serv. Oper. Manag. 2004, 6, 133-148. [CrossRef]

17. Umble, E.J.; Haft, R.R.; Umble, M.M. Enterprise resource planning: Implementation procedures and critical success factors. Eur. J. Oper. Res. 2003, 146, 241-257. [CrossRef]

18. Matoba, H.; Enomoto, M.; Watanabe, M.; Tsukishima, T. Production Planning System. U.S. Patent 5479343, 26 December 1995.

19. Tamaki, K.; Enomoto, M.; Tateishi, J.; Arai, Y.; Kato, Y. Production Planning System. U.S. Patent 6226561 B1, 1 May 2001.

20. Ishibashi, H.; Takizawa, N.; Nakagome, C.; Tateishi, J. Production Planning Method and Production Planning System. U.S. Patent 7693593 B2, 6 April 2010.

21. Ballard, H.G. The Last Planner System of Production Control. Ph.D. Thesis, University of Birmingham, Birmingham, UK, May 2000.

22. Magal, S.R.; Word, J. Integrated Business Processes with ERP Systems; Wiley Publishing: Hoboken, NJ, USA, 2011.

23. PlanetTogether PlanetTogether. Available online: https://www.planettogether.com/advanced-planning-andscheduling-solutions (accessed on 24 October 2020).

24. Siemens Opcenter APS. Available online: https://www.plm.automation.siemens.com/global/en/products/ manufacturing-operations-center/preactor-aps.html (accessed on 24 October 2020).

25. DassaultSystemes DELMIA Quintiq. Available online: https://www.3ds.com/products-services/delmia/ products/delmia-quintiq/ (accessed on 24 October 2020).

26. Lee, J.M.; Jeong, Y.-K.; Woo, J.H. Development of an evaluation framework of production planning for the shipbuilding industry. Int. J. Comput. Integr. Manuf. 2018, 31, 831-847. [CrossRef] 
27. Park, J.G.; Woo, J.H. A study on process management method of offshore plant piping material. J. Soc. Nav. Archit. Korea 2018, 55, 124-135. [CrossRef]

28. Floudas, C.A.; Lin, X. Mixed integer linear programming in process scheduling: Modeling, algorithms, and applications. Ann. Oper. Res. 2005, 139, 131-162. [CrossRef]

Publisher's Note: MDPI stays neutral with regard to jurisdictional claims in published maps and institutional affiliations.

(C) 2020 by the authors. Licensee MDPI, Basel, Switzerland. This article is an open access article distributed under the terms and conditions of the Creative Commons Attribution (CC BY) license (http://creativecommons.org/licenses/by/4.0/). 